\title{
Isolation and Characterization of Staphylococcus Aureus Phage and Its Anti-Biofilm Activity Individually or Collaborative with Streptomycin
}

Liming Jiang ( jlmsws@163.com )

Chinese Academy of Medical Sciences and Peking Union Medical College Institute of Medical Biology

Rui Zheng

First People's Hospital of Yunnan

\section{Research}

Keywords: Staphylococcus aureus, phage, endolysin, biofilm, streptomycin

Posted Date: May 29th, 2020

DOI: https://doi.org/10.21203/rs.3.rs-26824/v1

License: (c) (1) This work is licensed under a Creative Commons Attribution 4.0 International License.

Read Full License 


\section{Abstract}

Background: Staphylococcus aureus was a widespread of Gram-positive pathogen bacteria which causes a wide range of symptoms. Bacteria biofilm was the multicellular community of microorganisms that attached to non-biological and biological surfaces.

Method: Here, we aimed to isolation and characterization of $S$. aureus phage and research its bactericidal activity that individually or collaborative with streptomycin.

Results: In this study, virulent phage WX was isolated from slaughter house in Jiangsu, China. It's belonged to the Siphoviridae family and optimal growth temperature was $37^{\circ} \mathrm{C}$, the $\mathrm{pH}$ of optimal preservation buffer was $6 \sim 7$, optimal multiplicity of infection (MOI) was 0.01 and the genome size was 141,342 bp. Phage WX has can sterilize most clinical strains of $S$. aureus which was isolated from clinical patients in the first people's hospital of Yunnan province laboratory. Streptomycin has better antibiofilm effect than phage WX in low concentration culture of bacteria, nonetheless, phage WX has better anti-biofilm effect than streptomycin in high concentration culture of bacteria. Collaboration of phage WX and streptomycin have better anti-biofilm effect than alone of WX or streptomycin in low concentration culture of bacteria and phage WX have better anti-biofilm effect than streptomycin in high concentration culture of bacteria.

Conclusion: The data of this study provided a strong evidence of application phage for reduce the growth of $S$. aureus biofilm, this study was important for clinic and replace antibiotics in some extent.

\section{Introduction}

Staphylococcus aureus was a widespread of Gram-positive pathogen bacteria that causes a wide range symptoms of gastroenteritis, subclinical and clinical mastitis, skin and soft tissue, osteoarticular, pleuropulmonary, bacteremia, mastitis, anterior nares, nosocomial infections, infective endocarditis and device related infections [1-6]. With the broader application and abusing of methicillin, vancomycin and trimethoprim-sulfamethoxazole that leading emergence of many resistant bacteria [7, 8]. S. aureus wound infection were strongly associated with the formation of biofilm communities [9]. Futhermore, human organs and medical devices were also the medium for biofilm. Fortunately, phages have a strong ability to clear biofilm $[10,11]$.

Bacterial biofilm was the multicellular community of microorganisms that embedded self-produced extracellular matrix that attached to highly hydrated extracellular matrixon, biological surfaces and nonbiological [12-14]. The extracellular polymeric substances matrix of biofilm acts as a barrier that reduces the penetration of antimicrobial agents into the interior of biofilm $[15,16]$. Biofilm were highly resistant to desiccation, heat, antibiotics and acidic condition [17]. Bacteria in biofilm were approximately 10 to 1000 times less sensitive to antimicrobial agents than planktonic bacteria, on account of extracellular polymeric substances of the biofilm that prevent contact with antimicrobial agents $[18,19]$. Which makes totally eliminate of biofilm among husbandry, food industry and clinic were scarcely possible [20]. 
With the aggravation abuse of antibiotic resulting the problem of multiple resistant bacteria (MRB). In 2003 , there have 80,000 death annually which caused by abuse of antibiotics in China [21]. Phages and their derivatives were ideal candidates for replacing or compensating of antibiotic problems in the future [22]. Phage has the ability of sterilize bacteria 23,24$]$. Due to ability of kill bacteria, which appear to be a good alternative to antimicrobials and disinfectants. Above all, phage only infect bacteria and not be harmful to humans, making them safe for apply in clinic and food products [25]. Recent study found that phage has high efficiency in reducing and control of bacterial biofilms on various surfaces that formed by Escherichia coli, Salmonella, Listeria monocytogenes and Pseudomanas aeruginosa [26-30].

In this article, we have isolated and characterized a lytic $S$. aureus phage WX. Prevention and control of contamination that caused by $S$. aureus biofilm has great importance for economic point and medical. Afterwards, we have studied the basic features of $S$. aureus phage WX. Therefore, the purpose of this study was to reduce $S$. aureus biofilm formation or control mature biofilms through phage WX. Our aim was to determine whether phage could be used as an alternative therapeutic agent against multidrugresistant bacterial strains, specifically for $S$. aureus strains.

\section{Materials And Methods}

\section{Bacterial strains and growth conditions}

S. aureus was isolated from a clinic patient in Yunnan first people's hospital, China, it was used as host bacteria for isolate phages. The host strain and phage host range determination strains were grown aerobically on BHI plates or in BHI broth (Difco, Detroit, MI, USA) and incubated in $37^{\circ} \mathrm{C}$. Soft top agar containing of $0.5 \%(\mathrm{w} / \mathrm{w})$ agar in $\mathrm{BHI}$ broth for phage plaque confirmation and $\mathrm{BH}$ agar plates containing of $1.8 \%(\mathrm{w} / \mathrm{w})$ agar. All S. aureus strains were stored in $-80^{\circ} \mathrm{C}$ in BHI broth (Difco, Detroit, MI, USA) containing of $20 \%(\mathrm{v} / \mathrm{v})$ glycerol.

\section{Phage isolation and purification}

S. aureus targeting phages were isolated from pig slaughter house. The phages isolate method was modified as follows [31]. Briefly, $10 \mathrm{~g}$ of pig farm trash can was mixed with $20 \mathrm{~mL}$ of sterile normal saline $(0.9 \% \mathrm{NaCl})$ buffered in $50 \mathrm{~mL}$ sterile centrifuge tube and then shocked incubator of $200 \mathrm{rpm}$ for $2 \mathrm{~h}$ in room temperature. Then, samples were centrifuged at $5000 \times \mathrm{g}$ for $15 \mathrm{~min}$ and filtered with $0.22 \mu \mathrm{m}$ filter membrane. $10 \mathrm{~mL}$ of each filtering medium was added to $30 \mathrm{~mL}$ of $\mathrm{BHI}$ broth that containing of $1 \%(\mathrm{v} / \mathrm{v})$ of overnight culture of the host strain and then incubated for $48 \mathrm{~h}$. After that, Cultures were centrifuged for $8000 \times \mathrm{g}, 15 \mathrm{~min}$ and the supernatant was filtered with $0.22 \mu \mathrm{m}$ filter membrane. The filtrate was diluted 10 times in series and mixing with $5 \mathrm{~mL}$ of molten BHI soft agar that containing of $S$. aureus ( $2 \times$ $10^{8} \mathrm{cfu} / \mathrm{mL}$ ), and immediately added to $\mathrm{BHI}$ plate. Overnight culture and plaque formation was observed. Single phage plaque was selected for phage purification and repeated for three times. 


\section{The $\mathrm{pH}$, thermotolerance, $\mathrm{MOI}$, growth curve and TEM of isolated phage Optimum pHखMOI and thermotolerance}

The phage WX stock was diluted to $1 \times 10^{8} \mathrm{pfu} / \mathrm{mL}$ with $\mathrm{BH}$ broth. Take of $0.99 \mathrm{~mL}$ liquid buffer for $\mathrm{pH}$ of $3,4,5,6,7,8,9,10$ and 11 (50 mmol/L Citrate buffer, $\mathrm{pH} 3, \mathrm{pH} \mathrm{4,} \mathrm{pH} \mathrm{5;} 50 \mathrm{mmol} / \mathrm{L}$ phosphate buffer, $\mathrm{pH}$ 6, pH 7, pH 8; $50 \mathrm{mmol} / \mathrm{L}$ Tris-HCl buffer, $\mathrm{pH} 9 ; 50 \mathrm{mmol} / \mathrm{L}$ Sodium carbonate buffer, $\mathrm{pH}$ 10, $\mathrm{pH}$ 11) in $1.5 \mathrm{~mL}$ sterile centrifuge tube, added $0.01 \mathrm{~mL}$ of diluted phage $\mathrm{WX}$ for titer of $1 \times 10^{6} \mathrm{pfu} / \mathrm{mL}$ to each tube. Place at room temperature for $1 \mathrm{~h}$ then detection the titer of phage $\mathrm{WX}$ in different $\mathrm{pH}$ buffer. The experiments were repeated for three times. Thermotolerance detection were placed of $1 \mathrm{~mL}$ diluted phage WX in temperature controller of $4{ }^{\circ} \mathrm{C}, 25^{\circ} \mathrm{C}, 37^{\circ} \mathrm{C}, 42^{\circ} \mathrm{C}, 50^{\circ} \mathrm{C}, 60^{\circ} \mathrm{C}$ and $90^{\circ} \mathrm{C}$ for $1 \mathrm{~h}$, respectively. Multiplicity of infection (MOI) was the ratio of phages to host bacteria of initial infection. According to the MOI of $0.0001,0.001,0.01,0.11,10$ and 100 added phage WX stocks and $S$. aureus culture, cultured in $37^{\circ} \mathrm{C}$ for $8 \mathrm{~h}$. The culture were centrifuged at $10000 \times \mathrm{g}$ for $15 \mathrm{~min}$ in $4{ }^{\circ} \mathrm{C}$, then supernatant was filtered with $0.22 \mu \mathrm{m}$ filter and the titer of phage increment solution were determined through double plate method, the experiment was repeated for three times. For growth curve measure, $1 \times 10^{8} \mathrm{pfu} / \mathrm{mL}$ of phage WX were added to $\mathrm{BHI}$ culture containing of $1 / 250 \mathrm{~S}$. aureus seed culture according the optimum $\mathrm{MOI}$ and shacked culture in $37{ }^{\circ} \mathrm{C}$, intermittent sampling was used to determine the titer of phage.

\section{Transmission electron microscopy}

The morphology of the phage particles was observed by transmission electron microscopy (TEM). Briefly, each phage stock dilution (approximately $2 \times 10^{8}$ to $2 \times 10^{9} \mathrm{pfu} / \mathrm{mL}$ ) was deposited on copper grids with carbon-coated Formvar films, stained with $2 \%$ uranyl-acetate $(\mathrm{pH} \mathrm{4.0)}$. Phage samples were imaged using a Philips EM 300 electron microscope, operated at 80 kV in Jiangnan university (Wuxi, China). Phage was classified and identified referring to the International Committee on Taxonomy of Viruses (Rodhain et al., 1995).

\section{Phage genome DNA extraction, sequencing and bioinformatics analysis}

Firstly, phage was purified from concentrated to a high titer stock with $10 \mathrm{kDa}$ filter (about $10^{9}$ to $10^{10}$ ). Purified phage was treated with RNase and DNase in $37^{\circ} \mathrm{C}$ for $1 \mathrm{~h}$. Then, Takara minibest viral RNA/DNA Extraction kit (Cat\#9766) was carried out to obtain purified phage genome DNA. Restriction endonuclease Ecorl, Hind III, Not I and Xhol I were used for phage genome digestion, respectively. Extracted phage genomic DNA was sequenced using a Illumina Hiseq (Sangon Biotech, China). The original sequencing data were evaluated by FastQC and assembled with SPAdes assembler software. The NCBI Blast compare with multiple databases of CDD, KOG, COG, NR, NT, PFAM, Swissprot and TrEMBL were used for function annotation information of gene protein sequence. 


\section{Phage lytic spectrum and antimicrobial susceptibility of $S$. aureus}

The host range of the phage WX was determined by the spot test method [32]. The reference strains ( All strains were isolated from clinical patients) were tested for susceptibility of phage WX. Generally, each of $200 \mathrm{uL}$ reference strains $\left(10^{9} \mathrm{cfu} / \mathrm{mL}\right.$ ) was added to $5 \mathrm{~mL}$ of liquefied BHI soft agar (BHI broth with $0.5 \%$ $(\mathrm{w} / \mathrm{w})$ agar), and poured over to $\mathrm{BHI} 1.8 \%(\mathrm{w} / \mathrm{w})$ agar plate. Three minutes later, single drops of phage suspension were added and incubated in $37^{\circ} \mathrm{C}$ for $24 \mathrm{~h}$. Antibiotic sensitivity of $S$. aureus strains were tested against seventeen antibiotics by minimal inhibitory concentration (MIC) method. The antimicrobials tested were Penicillin, Streptomycin, Kanamycin sulfate, Gentamicin, Ciprofloxacin, Levofloxacin, Rifampicin, Vancomycin, Erythromycin, Teicoplanin and Tetracycline.

\section{The different effects of phage and antibiotics on biofilms}

Make first-phase preparations, A 48 - well cell slide was placed into a 24 - well plate. Seed solution was inoculated into $100 \mathrm{~mL} \mathrm{BHI}$ culture solution at the rate of $4 \%$. Inoculate $1 \mathrm{~mL}$ of bacterial solution into 24-well plate. One group, added phage WX, streptomycin, and mixtures of streptomycin and phage WX, respectively, nothing added as control (The addition amount of phage was $\mathrm{MOI}=1$, The final concentration of streptomycin was $10 \mu \mathrm{g} / \mathrm{ml})$, Incubation $\left(37^{\circ} \mathrm{C}, 24 \mathrm{~h}\right)$. The other group, firstly, host culture for 12 hours, after that, added phage, streptomycin, and mixtures of streptomycin and phage, respectively, nothing added as control (The addition amount of phage was $\mathrm{MOI}=1$, the final concentration of streptomycin was $10 \mu \mathrm{g} / \mathrm{ml})$, Incubation $\left(37^{\circ} \mathrm{C}, 12 \mathrm{~h}\right)$. The cfu of each sample was measured through plate counting method. Following, the recovered culture washed twice with PBS buffer; and fixed with $2.5 \%$ pre-cooling glutaraldehyde at room temperature for $3 \mathrm{~h}$ in dark place. Wash twice with PBS buffer, then dehydrated in an increasing ethyl alcohol gradient (15\%,30\%, 50\%, 70\%, 100\% v/v) for 10 min for each step. Afterward, dry overnight and gilt, the results obtained through scanning electron microscope with an accelerating voltage of $20 \mathrm{kV}$. S. aureus seed solution was inoculated in $\mathrm{BH}$ for the proportion of $4 \%$ of overnight culture. Then 200 times dilution with $\mathrm{BHI}$ and added to 96 -well plate (200 $\mathrm{uL} /$ hole), each sample has three multiple holes. One group, added phage, streptomycin, and mixtures of streptomycin and phage, respectively, nothing added as control (The addition amount of phage was $\mathrm{MOI}$ $=0.1$, the final concentration of streptomycin was $10 \mu \mathrm{g} / \mathrm{ml})$, incubation $\left(37^{\circ} \mathrm{C}, 24 \mathrm{~h}\right)$. The other group, firstly, host culture for 12 hours, after that, added phage, streptomycin, and mixtures of streptomycin and phage, respectively, nothing added as control (The addition amount of phage was $\mathrm{MOI}=0.1$, the final concentration of streptomycin was $10 \mu \mathrm{g} / \mathrm{ml})$, incubation $\left(37^{\circ} \mathrm{C}, 12 \mathrm{~h}\right)$. The bacterial population density $\left(\mathrm{OD}_{600} \mathrm{~nm}\right)$ was measured using a ELIASA (Thermo Scientific, EUA) and discarded bacteria solution. The wells washed twice with PBS to remove unattached bacteria, repeated three times, added of $99 \%$ methanol and fix for $15 \mathrm{~min}$, then discard methanol and dry at room temperature, following added $2 \%$ crystal violet and stain for $8 \mathrm{~min}$. Rinse the culture plate with running water until the water is colorless. 
After drying, measured the absorption light at $570 \mathrm{~nm}$ wavelength with a microplate reader. The experiment was repeated for three times.

\section{Results}

\section{Characteristics and morphology of isolated phages}

Virulent $S$. aureus phage WX was isolated from pig farm trash can in Wuxi China. The plaque of phage WX was appeared $1 \mathrm{~mm}$ in diameter after overnight incubation at $37^{\circ} \mathrm{C}$ (Fig. 1.A). Negatively stained of purified $S$. aureus phage WX was observed with an electron microscope. Transmission electron microscopy (TEM) revealed phage WX virion with an icosahedral head of $80 \pm 2 \mathrm{~nm}$ in diameter, and a non contractile tail of $200 \pm 5 \mathrm{~nm}$ long (Fig. 1.C). The morphology of phage WX indicated it was belonged to Siphoviridae family. One step growth curve of the phage WX was obtained by inoculation on $S$. aureus according to $\mathrm{MOI}$ of 0.1 in $37^{\circ} \mathrm{C}$ (Fig. 1.B). The latent period for the phage WX was $60 \mathrm{~min}$. The titer of phage $W X$ was reached peaks very quickly in $5 \mathrm{~h}$ and appear going down after 20 hours later. The burst size of phage WX was approximately 300 times.

\section{Optimum temperature, $\mathrm{pH}$ and $\mathrm{MOI}$ of isolated phages}

Phage $W X$ has the highest activity after treatment for $1 \mathrm{~h}$ at $42^{\circ} \mathrm{C}$, then there was a noticeable decline at $60{ }^{\circ} \mathrm{C}$ and complete inactivation until $90^{\circ} \mathrm{C}$ (Fig. 2). The result show that phage WX has low temperature adaptability and which consistent with the optimum survival temperature of it's host. Phages WX has the most plaque at $\mathrm{pH}=6 \sim 7$, further, plaque at $\mathrm{pH}=10 \sim 11$ and $\mathrm{pH}=3 \sim 4$ were significantly decreased (Fig. 2). These results indicated that the phage WX intolerant to alkali and acids. Multiplicity of infection $(\mathrm{MOI})$ refers the ratio of the number of phages to cells. The optimum $\mathrm{MOI}$ of phage $\mathrm{WX}$ was 0.01 , among them, the plaque of $\mathrm{WX}$ was decreased significantly after 0.1 and reach minimum at $\mathrm{MOI}=100$ (Fig. 2).

\section{Characteristic and analysis of genome}

The genome size of phage WX was 141, $342 \mathrm{bp}$. We have identified of 204 protein-coding genes (open reading frames (ORFs) for complete genome (Table S1). WX DNA was digested by EcoR I and Hind III but can't be digested by Notl and Xhol I. Genome analysis revealed that phage WX was a virulent phage (Fig. 1.D, Fig. 3).

\section{Phage lytic spectrum and antibiotic resistance of $S$. aureus}

The $S$. aureus strains were isolated from clinical patients in the laboratory of first people's hospital of Yunnan province. Unfortunately, they have a broad spectrum of resistance (Table 1), but fortunately, most of them can be removed by the phage WX (Table 2). They were all possess resistant to Penicillin, 
kanamycin sulfate, Erythromycin and tetracycline, but sensitive to Streptomycin, Gentamicin, Ciprofloxacin, Levofloxacin, Rifampicin. The lytic of $S$. aureus phage WX was able to infect four $S$. aureus strains which were isolated from the First People Hospital of Yunnan Province, China (Table 2). This analysis underlined the wide host range of the isolated phage WX.

Table 1

Antibiotic resistance of $S$. aureus isolates used in this study

\begin{tabular}{|c|c|c|c|c|c|c|c|c|c|c|c|c|}
\hline \multirow[b]{2}{*}{ Antibiotic } & \multicolumn{12}{|c|}{ Staphylococcus aureus } \\
\hline & A & B & C & D & E & $\mathrm{F}$ & G & $\mathrm{H}$ & 1 & $J$ & MSSA & Sau \\
\hline Penicillin & $\mathrm{R}$ & $\mathrm{R}$ & $\mathrm{R}$ & $\mathrm{R}$ & $\mathrm{R}$ & $\mathrm{R}$ & $\mathrm{R}$ & $\mathrm{R}$ & $\mathrm{R}$ & $\mathrm{R}$ & $\mathrm{R}$ & $\mathrm{R}$ \\
\hline Streptomycin & S & $S$ & $S$ & $S$ & $S$ & $S$ & $S$ & $S$ & $S$ & $S$ & $S$ & $S$ \\
\hline kanamycin sulfate & $\mathrm{R}$ & $\mathrm{R}$ & $\mathrm{R}$ & $\mathrm{R}$ & $\mathrm{R}$ & $\mathrm{R}$ & $\mathrm{R}$ & $\mathrm{R}$ & $\mathrm{R}$ & $\mathrm{R}$ & $\mathrm{R}$ & $\mathrm{R}$ \\
\hline gentamicin & S & $S$ & $S$ & $S$ & $S$ & $S$ & $S$ & $S$ & $S$ & $S$ & $S$ & $S$ \\
\hline Ciprofloxacin & $S$ & $S$ & $S$ & $S$ & $S$ & $S$ & $S$ & $S$ & S & $S$ & $S$ & $S$ \\
\hline levofloxacin & $S$ & $S$ & S & $S$ & $S$ & $S$ & $S$ & $S$ & $S$ & $S$ & S & $S$ \\
\hline rifampicin & $S$ & S & S & $S$ & $S$ & $S$ & $S$ & $S$ & $S$ & $S$ & S & $S$ \\
\hline vancomycin & $S$ & S & $S$ & $S$ & $S$ & $S$ & $S$ & S & $S$ & $S$ & $S$ & $S$ \\
\hline Erythromycin & $S$ & $\mathrm{R}$ & $S$ & $\mathrm{R}$ & $\mathrm{R}$ & $\mathrm{R}$ & $\mathrm{R}$ & $\mathrm{R}$ & $S$ & $S$ & $\mathrm{R}$ & $S$ \\
\hline teicoplanin & $S$ & $S$ & $S$ & $S$ & $S$ & $S$ & $S$ & S & $S$ & $S$ & $S$ & $S$ \\
\hline tetracycline & $\mathrm{S}$ & S & $\mathrm{s}$ & $\mathrm{S}$ & $\mathrm{S}$ & $S$ & $\mathrm{R}$ & $\mathrm{R}$ & $\mathrm{R}$ & $\mathrm{R}$ & $\mathrm{R}$ & $\mathrm{R}$ \\
\hline
\end{tabular}


Table 2

Host range analysis of phage WX.

\begin{tabular}{|lc|}
\hline Strain & WX \\
\hline Staphylococcus aureus-A & - \\
\hline Staphylococcus aureus-B & - \\
\hline Staphylococcus aureus-C & - \\
\hline Staphylococcus aureus-D & - \\
\hline Staphylococcus aureus-E & - \\
\hline Staphylococcus aureus-F & - \\
\hline Staphylococcus aureus-G & - \\
\hline Staphylococcus aureus-H & $\square$ \\
\hline Staphylococcus aureus-I & - \\
\hline Staphylococcus aureus-J & $\square$ \\
\hline Staphylococcus aureus-MSSA & $\square$ \\
\hline Staphylococcus aureus-Sau & $\square$ \\
\hline
\end{tabular}

\section{Compare the effects of phages and streptomycin on host biofilm}

SEM was used to assess $S$. aureus biofilm formation on round coverslip that was affected by phage WX $(\mathrm{MOI}=0.1)$ and streptomycin $(10 \mu \mathrm{g} / \mathrm{mL})$. Under the condition of $S$. aureus inoculation at rate of $4 \%$, added phage $\mathrm{WX}(\mathrm{MOI}=0.1)$ and streptomycin $(10 \mu \mathrm{g} / \mathrm{mL})$ in immediately and culture for 24 hours, streptomycin have better sterilization effect than phage WX whether in the case of scanning electron micrograph, $\mathrm{OD}_{600}$ of bacterial culture solution, or microplate reader $\mathrm{OD}_{570}$ of $S$. aureus biofilm (Fig. 4, $5,6)$. Nevertheless, under the condition of $S$. aureus inoculation at rate of $4 \%$ ond culture for 12 hours, then $\mathrm{WX}(\mathrm{MOI}=0.1)$ and streptomycin $(10 \mathrm{ug} / \mathrm{mL})$ were added and cultured for 12 hours, phage $\mathrm{WX}$ have better sterilization effect than streptomycin whether in the case of scanning electron micrograph, $\mathrm{OD}_{600}$ of bacterial culture solution, or microplate reader $\mathrm{OD}_{570}$ of $S$. aureus biofilm (Fig. $\left.4,5,6\right)$. In addition, under the condition of $S$. aureus inoculation at a rate of $4 \%$ ond culture for 12 hours, then WX $(\mathrm{MOI}=0.1)$ and streptomycin $(10 \mathrm{ug} / \mathrm{mL})$ were added and cultured for 12 hours, collaboration of phage and antibiotics have better sterilization effect than alone of phage WX or streptomycin whether in the case of scanning electron micrograph, $\mathrm{OD}_{600}$ of bacterial culture solution, or microplate reader $\mathrm{OD}_{570}$ of $S$. aureus biofilm (Fig. 4,5,6). The result of host colony-forming unit indicate collaboration of phage WX and streptomycin have better sterilization effect than alone of phage WX or streptomycin (Fig. 6). Meanwhile, under the 
condition of $S$. aureus inoculation at a rate of $4 \%$ and culture for 12 hours, then WX $(\mathrm{MOI}=0.1)$ and Streptomycin $(10 \mathrm{ug} / \mathrm{mL})$ were added and cultured for 12 hours, phage WX have better sterilization effect than streptomycin (Fig. 6).

\section{Discussion}

The $S$. aureus used in this study was isolated from a clinical patient in the first people's hospital of Yunnan province, China, Unfortunately, they were all possess the ability to resistant penicillin, kanamycin sulfate, erythromycin and tetracycline. The emerging of multidrug-resistant (MDR) strains urgent needing new measures to inhibit pathogens. With the rise of antibiotic abuse, multiple resistant bacteria and superbacteria hence a public health hazard. Phage, are dawn of this increasing drug resistance. The isolated $S$. aureus phage WX was ideal substitute for antibiotics for they strong endolysin performance. What's more, phage have better sterilization effect than antibiotics in a high concentration of bacteria, and that, collaboration of phages and antibiotics have better sterilization effect than alone of phages or antibiotics in a low concentration medium of bacteria (Fig. 4,5,6).

The isolated $S$. aureus phage WX was belong to Siphoviridae family and the genome sizes for 141 , $342 \mathrm{bp}$. Corresponding, the geonme sizes of $S$. aureus phage fRuSau02 for 148, $464 \mathrm{bp}$ and DRA88 for $141,907 \mathrm{bp}[33,34]$. The genome characteristics of phage WX reveal that has a special smalll endolysin with good ability lytic (Fig. 3).

Compared to antibiotics and phages, phage endolysin has many advantages as an antibacterial agent for clinic patients and combating food spoilage [35]. Phage endolysin was one-use enzymes that with a short half-life [36]. Guo found that $S$. aureus phage endolysin contains a catalytic domain of Ch-type lysozyme at the $\mathrm{N}$-terminus, and this functional area is able to cleave the 6-0-acetylated peptidoglycans which present in the cell wall of $S$. aureus. Comparative, the use of a endolysin as an alternative for antibiotics and phages to inhibit pathogenic. At the same time, there are some challenges for long-term control in the clinic and food industry for the strong vitality of $S$. aureus $[37,38]$.

The ability of microorganism to form biofilm on different food surfaces increases the risk of crosscontamination, particularly in poultry products, which was a serious problem for food industries, clinic and public health [39-41]. S. aureus biofilms in catheter sites and wounds present important problems to patients, drug resistance, morbidity and mortality [33]. Although the significant problems in pathogen control caused by biofilms, exploiting effective eliminate of biofilms is still challenging [42]. Until now, there is no ideal technology of biofilm control, hence, the new control strategies for biofilm are constantly recommended [43]. In this study, we demonstrated that the phage WX has better properties than antibiotics to reduced biofilm formation of $S$. aureus (Fig. 4,5,6).

The result shown that phage WX and Streptomycin can infect $S$. aureus biofilm and has the potential to reduce tested $S$. aureus strains. Antibiotics have better anti-biofilm effect than phages in a low concentration medium of bacteria (Fig. 4,5,6). Nonetheless, phages have better anti-biofilm effect than antibiotics in a high concentration of bacteria (Fig. 4,5,6). The data of this study provided the strong 
evidence that the application of phage could reduce the growth and biofilm of $S$. aureus that are important to maintain public health.

In this study, the novel $S$. aureus phage WX, which has good bactericidal and anti-biofilm property on condition of that phage WX endolysin just contains 57 amino acids. This study provides a solid theoretical basis for the study of Staphylococcus aureus phage endolysin.

\section{Conclusion}

In conclusion, firstly, we have isolated and characterizated of a lytic Staphylococcus aureus phage and acquired its biological propertiesits, then, we have found that combination use of phages and antibiotics possess significantly better anti-biofilm and bactericidal properties on host bacteria than either antibiotics or phages alone. The data of this study provided the strong evidence that the application of phage could reduce the growth and biofilm of Staphylococcus aureus that are important to maintain public health.

\section{Abbreviations}

S: sensitive; R: resistive; cfu: colony-forming unit; pfu: plaque forming unit; MOI: Multiplicity of Infection

\section{Declarations}

\section{Authors' contributions}

Conceived and designed the experiments: LMJ. Performed the experiments: LMJ. Analyzed the data: LMJ. Contributed reagents/materials/analysis tools: RZ, LMJ. Wrote the paper: LMJ. Both authors read and approved the final manuscript.

\section{Acknowledgements}

Not applicable

\section{Funding}

The authors gratefully acknowledge the financial support provided by National Key Research and Development Program of China (2017YFC1601704), Projects 31522044, 31671909, and 31772034 of the National Natural Science Foundation of PR China and Program of Jiangsu Key Laboratory of Advanced Food Manufacturing Equipment \& Technology (FMZ201904), National First-class Discipline Program of Food Science and Technology (JUFSTR20180205). Sponsored by K.C.Wong Magna Fund in Ningbo University. 


\section{Ethics Statement}

Ethical approval was obtained from the Institutional Ethics Committee

(The First People's Hospital of Yunnan Province, Kunming, Yunnan, China ). The study protocol was in accordance with the Declaration of Helsinki for Human Research of 1974 (last modified in 2000). Written informed consent was received from each patient before sample collection.

\section{Availability of data and material}

Please contact author for data requests.

\section{Consent for publication}

Not applicable.

\section{Conflicts of Interest}

The authors declare no conflict of interest.

\section{References}

1. Dinges, M.M., Orwin, P.M., Schlievert, P.M., 2000. Enterotoxins of Staphylococcus aureus. Clinical Microbiology Reviews. 13, 16-34.

2. Leitner, G., Lubashevsky, E. and Trainin, Z., 2003. Staphylococcus aureus vaccine against mastitis in dairy cows, composition and evaluation of its immunogenicity in a mouse model. Vet Immunol Immunopathol. 93, 159-167.

3. O'Flaherty, S., Ross, R.P., Meaney, W., 2005. Potential of the polyvalent anti-Staphylococcus bacteriophage $\mathrm{K}$ for control of antibiotic-resistant staphylococci from hospitals. Appl Environ Microbiol. 7, 1836-18420.

4. Tong, S.Y., Davis, J.S., Eichenberger, E., Holland, T.L., Fowler, V.G.J.,2015. Staphylococcus aureus infections: epidemiology, pathophysiology, clinical manifestations, and management. Clin Microbiol Rev. 28, 603-661.

5. Lowy, F.D., 1998. Staphylococcus aureus infections. N Engl J Med. 339, 520-532.

6. Foster, T.J., 2005. Immune evasion by staphylococci. Nat Rev Microbiol. 3, 948-958.

7. Chang, S., Sievert, D.M., Hageman, J.C., Boulton, M.L., Tenover, F.C., Downes, F.P., Shah, S., Rudrik, J.T, Pupp, G.R., Brown, W.J., Cardo, D., Fridkin, S.K., 2003. Infection with vancomycin-resistant Staphylococcus aureus containing the vanA resistance gene. N. Engl. J. Med. 348, 1342-1347 
8. Appelbaum, P.C., Bozdogan, B., 2004.Vancomycin resistance in Staphylococcus aureus. Clin Lab Med. 24, 381-402

9. Erol, S., Altoparlak, U., Akcay, M.N., Celebi, F., Parlak, M., 2004. Changes of microbial flora and wound colonization in burned patients. Burns. 30, 357-361.

10. Percival, S.L., Hill, K.E., Williams, D.W., Hooper, S.J., Thomas, D.W., Costerton, J.W., 2012. A review of the scientific evidence for biofilms in wounds.Wound Repair Regen. 20, 647-657.

11. Otto, M., 2013. Staphylococcal infections: mechanisms of biofilm mat uration and detachment as critical determinants of pathogenicity. Annu Rev Med. 64, 175-188.

12. Branda, S.S., Vik, A., Friedman, L., Kolter, R., 2005. Biofilms: The matrix revisited.Trends in Microbiology. 13, 20-26.

13. Flemming, H.C., Wingender, J., 2010. The biofilm matrix. Nat Rev Microbiol. 8, 623-33.

14. Hall-Stoodley, L., Costerton, J.W., Stoodley, P., 2004. Bacterial biofilms: From the natural environment to infectious diseases. Nature Reviews Microbiology. 2, 95-108.

15. Donlan, R.M., Costerton, J.W 2002. Biofilms: Survival mechanisms of clinically relevant microorganisms. Clinical Microbiology Reviews, 15, 167.

16. Marchand, S., De Block, J., De Jonghe, V., Coorevits, A., Heyndrickx, M., Herman, L., 2012. Biofilm formation in milk production and processing environments; influence on milk quality and safety. Comprehensive Reviews in Food Science and Food Safety. 11, 133-147.

17. Davies, D., 2003. Understanding biofilm resistance to antibacterial agents. Nature Reviews Drug Discovery. 2, 114-122.

18. Luppens, S.B., Rei, M.W., van der Heijden, R.W., Rombouts, F.M., Abee, T.,2002. Development of a standard test to assess the resistance of Staphylococcus aureus biofilm cells to disinfectants. Applied and Environmental Microbiology. 68, 4194-4200.

19. Penesyan, A., Gillings, M., Paulsen, I.T., 2015. Antibiotic discovery: Combatting bacterial resistance in cells and in biofilm communities. Molecules, 20, 5286-5298.

20. Kumari, S., Sarkar, P.K., 2016. Bacillus cereus hazard and control in industrial dairy processing environment. Food Control. 69, 20-29.

21. Jay, J.M., 2000. Modern food microbiology. 6th ed. Gaithersburg, MD: Aspen Publishers. 679

22. Endersen, L., O'Mahony, J., Hil,I C., 2014. Phage therapy in the food industry. Annu Rev Food Sci Technol. 5, 327-349.

23. Chang, Y., Shin, H., Lee, J.H., Park, C.J., Paik, S.Y., Ryu, S., 2015. Isolation and genome characterization of the virulent Staphylococcus aureus bacteriophage SA97. Viruses. 7, 5225-5242

24. Kutter, E., Sulakvelidze, A., 2005. Bacteriophages: Biology and Applications. CRC Press, Boca Raton, FL 10, 2174

25. Gutierrez, D., Rodrıguez-Rubio, L., Martınez, B., Rodrıguez, A., Garcıa, P., 2016. Bacteriophages as weapons against bacterial biofilms in the food industry. Front Microbiol. 7, 825. 
26. Ahn, J., Kim, S., Jung, L.S, Biswas, D., 2013. In vitro assessment of the susceptibility of planktonic and attached cells of foodborne pathogens to bacteriophage P22-mediated Salmonella lysates. J Food Prot. 76, 2057-2062

27. Chandra, M., Thakur, S., Chougule, S.S., Narang, D., Kaur, G., Sharma, N.S., 2015. Combined effect of disinfectant and phage on the survivality of Salmonella Typhimurium and its biofilm phenotype. Int $\mathrm{J}$ Food Safety. 17, 25-31.

28. Garcia, K.C.O.D., Corrêa, I.M.O., Pereira, L.Q., Silva, T.M., Mioni, M.S.R., 2017. Bacteriophage use to control Salmonella biofilm on surfaces present in chicken slaughterhouses. Poult Sci. 96, 33923398

29. Gong, C., Jiang, X., 2017. Application of bacteriophages to reduce Salmonella attachment and biofilms on hard surfaces. Poult Sci. 96, 1838-1848.

30. Knezevic, P., Petrovic, O., 2008. A colorimetric microtiter plate method for assessment of phage effect on Pseudomonas aeruginosa biofilm. J Microbiol Methods. 74, 114-118.

31. Park, M., Lee, J.H., Shin, H., Kim., Choi, J., Kang, D.H., Heu, S., Ryu, S., 2012. Characterization and comparative genomic analysis of a novel bacteriophage, SFP10, simultaneously inhibiting both Salmonella enterica and Escherichia coli 0157:H7. Appl Environ Microbiol. 78, 58-69

32. Chopin, M.C., Chopin, A., Roux, C., 1976. Definition of bacteriophage groups according to their lytic action on mesophilic lactic streptococci. Applied and Environmental Microbiology. 32, 741-746.

33. Alves, A., Gaudion, J.E., Bean., 2014. Combined Use of Bacteriophage K and a Novel Bacteriophage To Reduce Staphylococcus aureus Biofilm Formation. Applied and Environmental Microbiology. 80, 6694-6703.

34. Katarzyna, L., Henni, T., Anu, W., 2017. Characterization of vB_SauM-fRuSau02, a Twort-Like Bacteriophage Isolated from a Therapeutic Phage Cocktail. Viruses. 9, 258.

35. Callewaert, L., Walmagh, M., Michiels, C.W., Lavigne, R., 2011. Food applications of bacterial cell wall hydrolases. Curr Opin Biotechnol. 22, 164-171

36. Fischetti, V.A., 2008. Bacteriophage lysins as effective antibacterials. Curr Opin Microbiol. 1,:393-400.

37. Delbes, C., Alomar, J., Chougui, N., Martin, J.F, Montel, M.C., 2006. Staphylococcus aureus growth and enterotoxin production during themanufacture of uncooked, semihard cheese from cows rawmilk. J Food Pro t.69, 2161-2167.

38. Mayer, M.J., Gasson, M.J., Narbad, A., 2012. Genomic sequence of bacteriophage ATCC 8074-B1 and activity of its endolysin and engineered variants against Clostridium sporogenes. Appl Environ Microbiol. 78, 3685-3692.

39. Al-Shabib, N.A., Husain, F.M., Ahmad, I., Khan, M.S., Khan, R.A., Khan, J.M., 2017. Rutin inhibits mono and multi-species biofilm formation by foodborne drug resistant Escherichia coli and Staphylococcus aureus. Food Control. 79, 325-332.

40. Grant, A., Hashem, F., Parveen, S., 2016. Salmonella and Campylobacter. antimicrobial resistance and bacteriophage control in poultry. Food Microbiol. 53, 104-109 
41. Shi, X., Zhu, X., 2009. Biofilm formation and food safety in food industries. Trends Food Sci Technol. 20, 407-413.

42. Cappitelli, F., Polo, A.,Villa, F., 2014. Biofilm formation in food processing environments is still poorly understood and controlled. Food Engineering Reviews. 6, 29-42.

43. Simoes, M., Simoes, L.C., Vieira, M.J., 2010. A review of current and emergent biofilm control strategies. Lwt-Food Science and Technology. 4, 573-583.

\section{Figures}

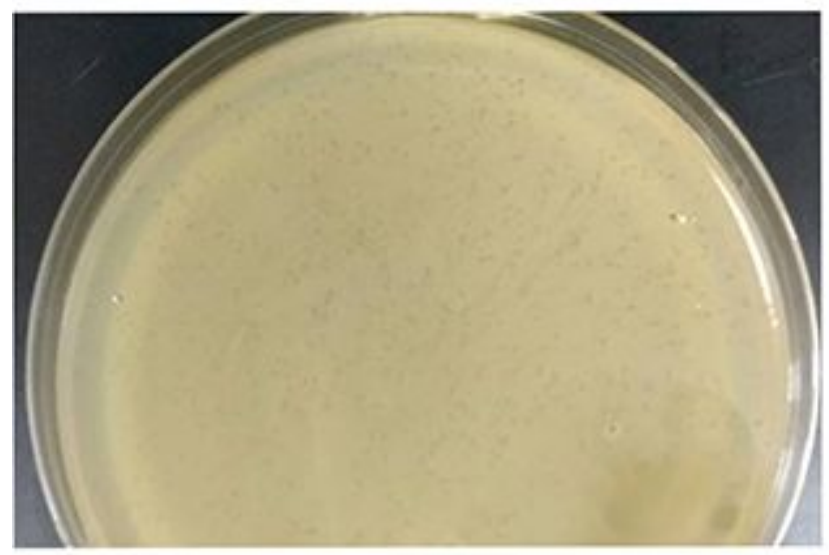

A

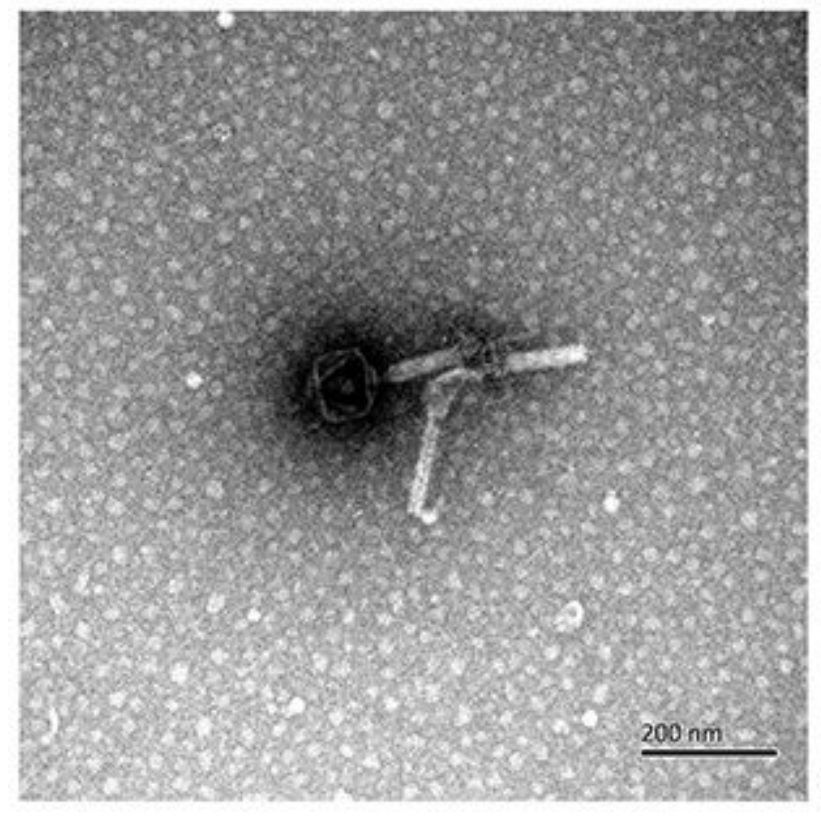

$\mathrm{C}$

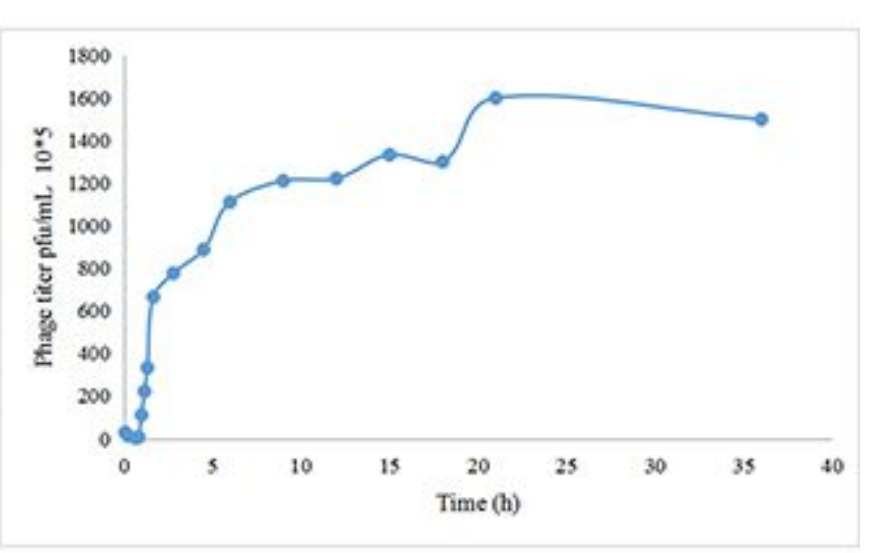

B

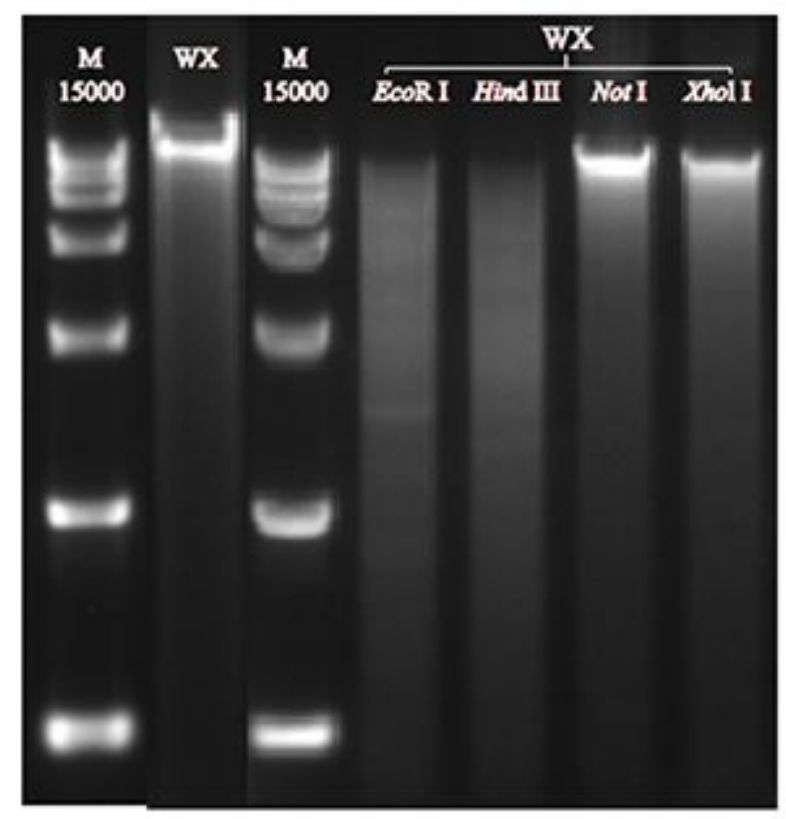

D

\section{Figure 1}

A. Plaques formed by Staphylococcus aureus phage WX, the host strains of $S$. aureus after an overnight incubation at $37^{\circ} \mathrm{C}$. B. Population dynamics of phage WX inoculate in S. aureus. C. Morphological features of $S$. aureus phage WX by transmission electron microscopy (TEM). D. Restriction enzyme 
digests of phage WX. Phage WX DNA was digested by EcoRI (lane 4) and Hind III (lane 5), whereas it can't be digested by Notl (lane 6) and Xhol I (lane 7).

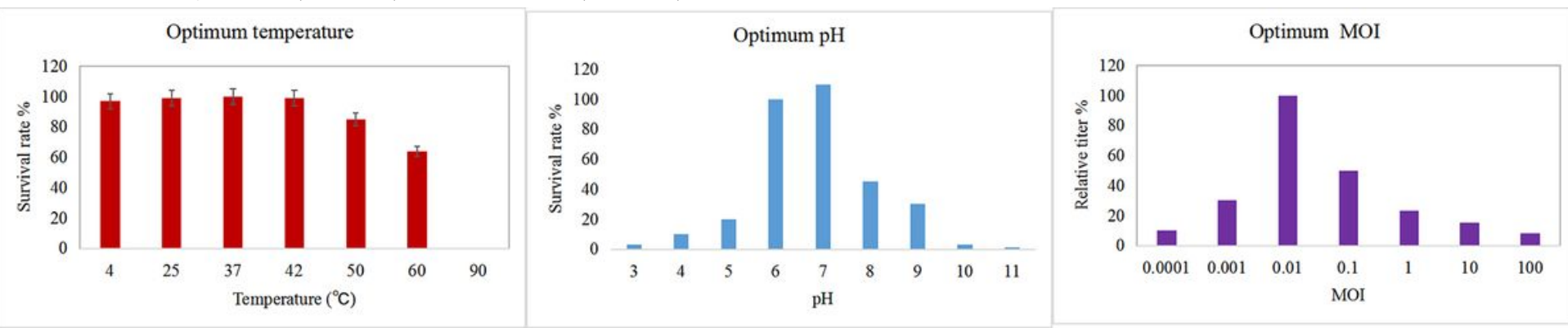

Figure 2

Optimum temperature, $\mathrm{pH}$ and $\mathrm{MOI}$ of isolated phage $\mathrm{WX}$.

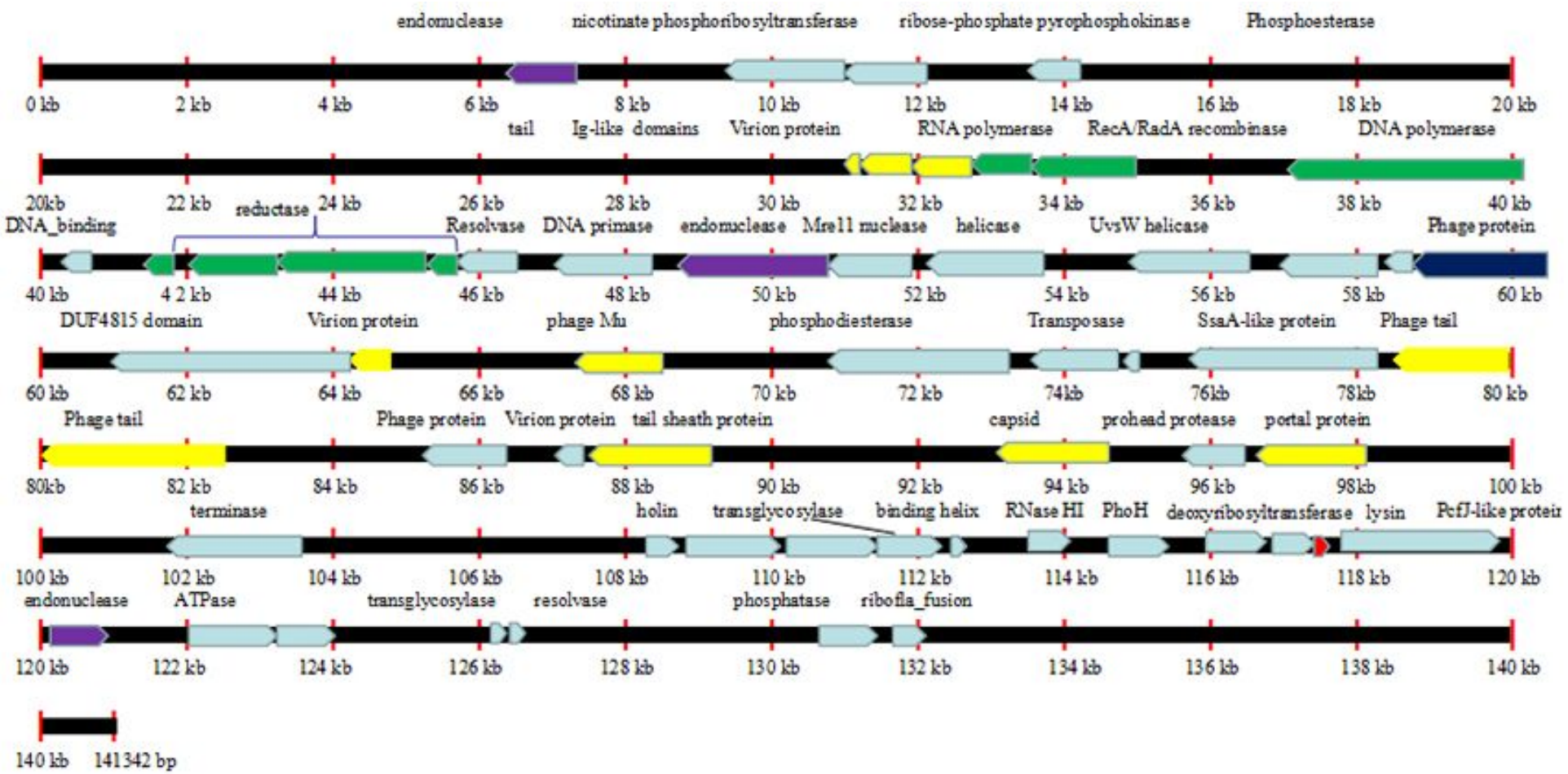

Figure 3

Line map of the phage WX genome. In the WX track, genes colored red instructions for lysozyme, genes colored yellow instructions for tail and genes colored purple instructions for endonuclease.The arrows represent the ORFs and point the direction of transcription. 


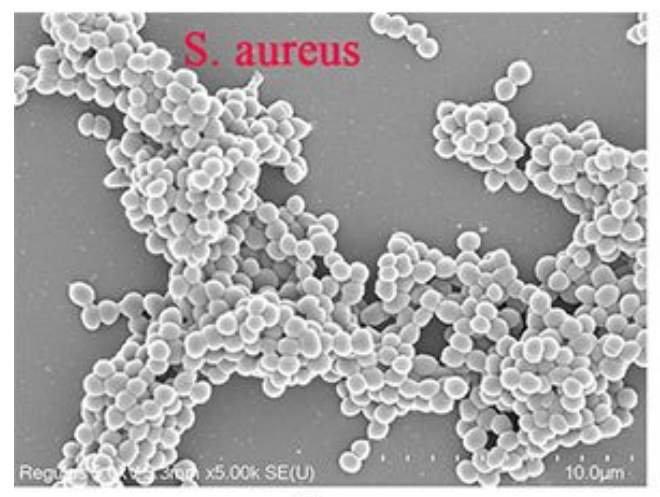

a

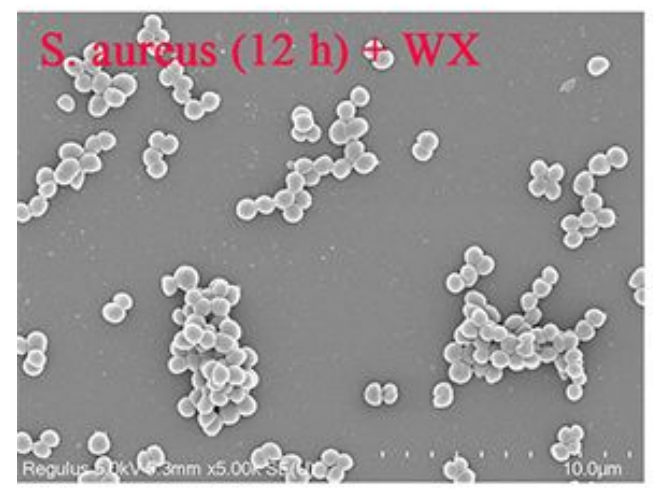

d

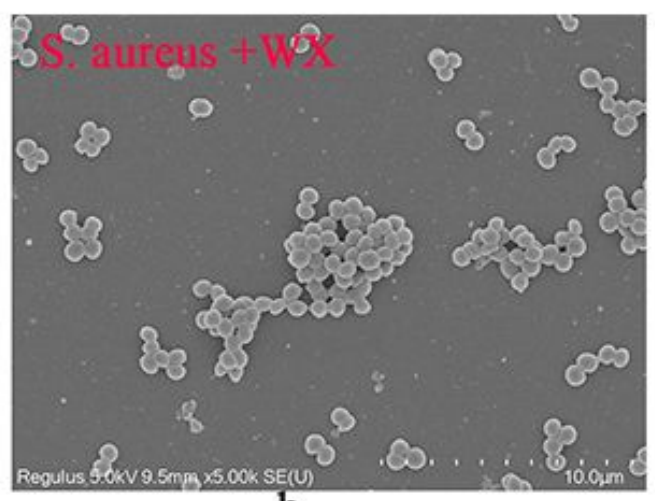

b

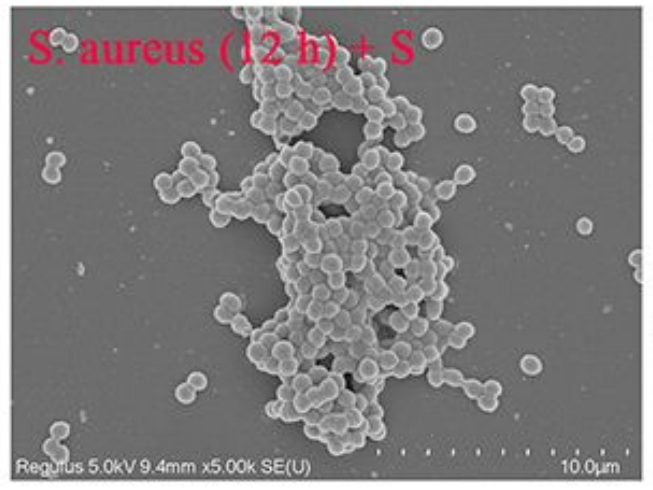

e

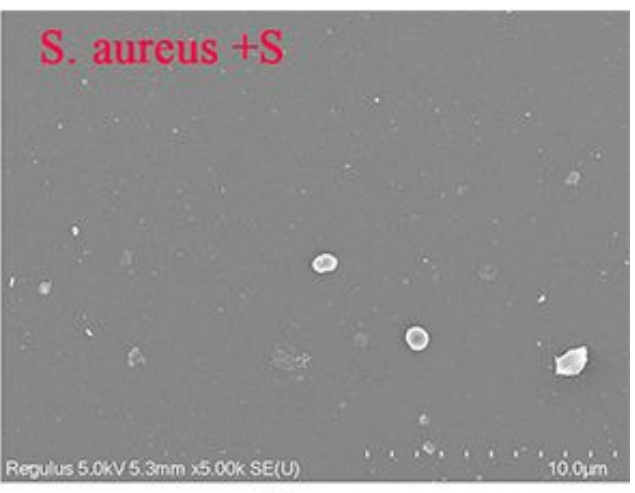

C

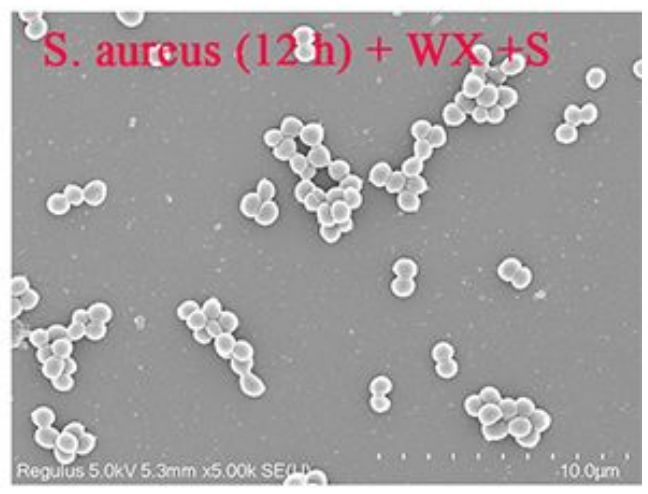

f

Figure 4

Scanning electron micrograph (SEM) of S. aureus colonization before and after phage WX $(\mathrm{MOI}=0.1)$ and Streptomycin (10 ug/mL) application to biofilms formed on round coverslip. (A) S. aureus inoculation at a rate of $4 \%$ and culture for 24 hours, (B) A added phage WX (MOI=0.1), (C) A added Streptomycin (10 $\mathrm{ug} / \mathrm{mL}$ ). (D) S. aureus inoculation at a rate of $4 \%$ and culture for 12 hours, then phage WX (MOI=0.1) was added and cultured for 12 hours, (E) S. aureus inoculation at a rate of $4 \%$ and culture for 12 hours, then Streptomycin (10 ug/mL) was added and cultured for 12 hours, $(F)$ S. aureus inoculation at a rate of $4 \%$ and culture for 12 hours, then phage $\mathrm{WX}(\mathrm{MOI}=0.1)$ and Streptomycin $(10 \mathrm{ug} / \mathrm{mL})$ were added and cultured for 12 hours. (5, 000× magnification)
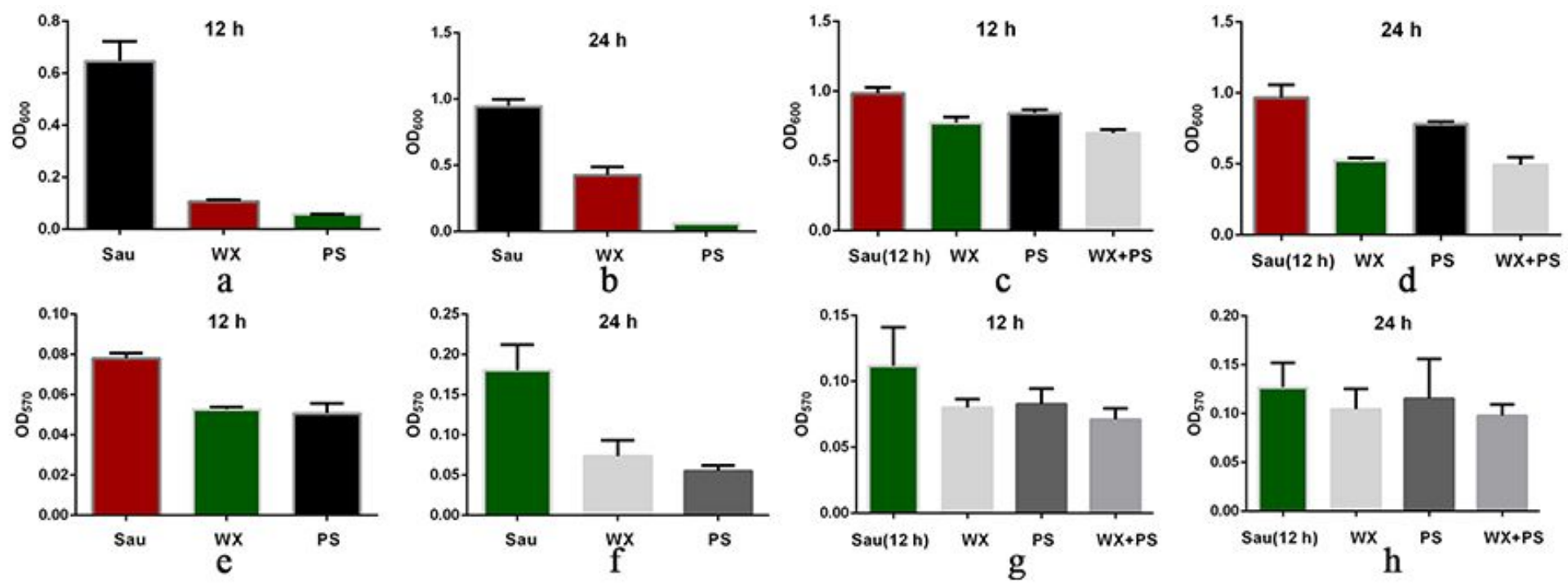


\section{Figure 5}

Effects of phage $W X$ and streptomycin $(10 \mathrm{ug} / \mathrm{mL})$ on biofilms. $(A, B)$ Effects of phage $W X$ and Streptomycin $(10 \mathrm{ug} / \mathrm{mL})$ on S. aureus (inoculation at a rate of $4 \%$ o) growth that culture for $12 \mathrm{~h}$ and $24 \mathrm{~h}$ (OD600). (E, F) Effects of phage WX and Streptomycin $(10 \mathrm{ug} / \mathrm{mL})$ on S. aureus (inoculation at a rate of $4 \%$ ) biofilm that culture for $12 \mathrm{~h}$ and $24 \mathrm{~h}$ (OD570). (C, D) Effects of phage WX and Streptomycin (10 $\mathrm{ug} / \mathrm{mL}$ ) on S. aureus (inoculation at a rate of $4 \%$ o) growth, first culture for 12 hours, then phage WX and Streptomycin (10 ug/mL) were added and cultured for $12 \mathrm{~h}$ and $24 \mathrm{~h}$ (OD600). (G,H) Effects of phage WX and Streptomycin $(10 \mathrm{ug} / \mathrm{mL})$ on S. aureus (inoculation at a rate of $4 \%$ o) biofilm, first culture for 12 hours, then phage $\mathrm{WX}$ and Streptomycin $(10 \mathrm{ug} / \mathrm{mL})$ were added and cultured for $12 \mathrm{~h}$ and $24 \mathrm{~h}$ (OD 570, ) .

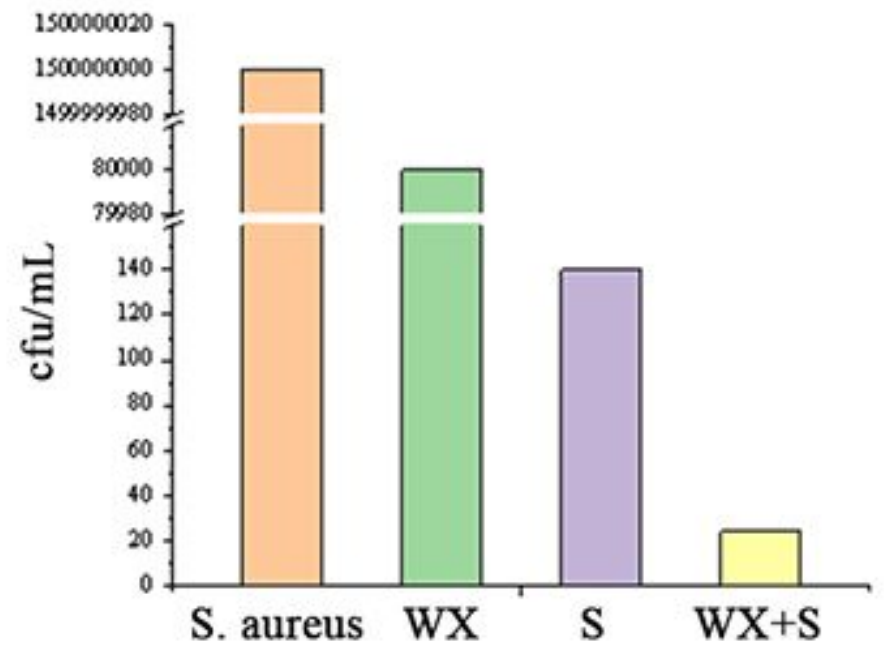

A

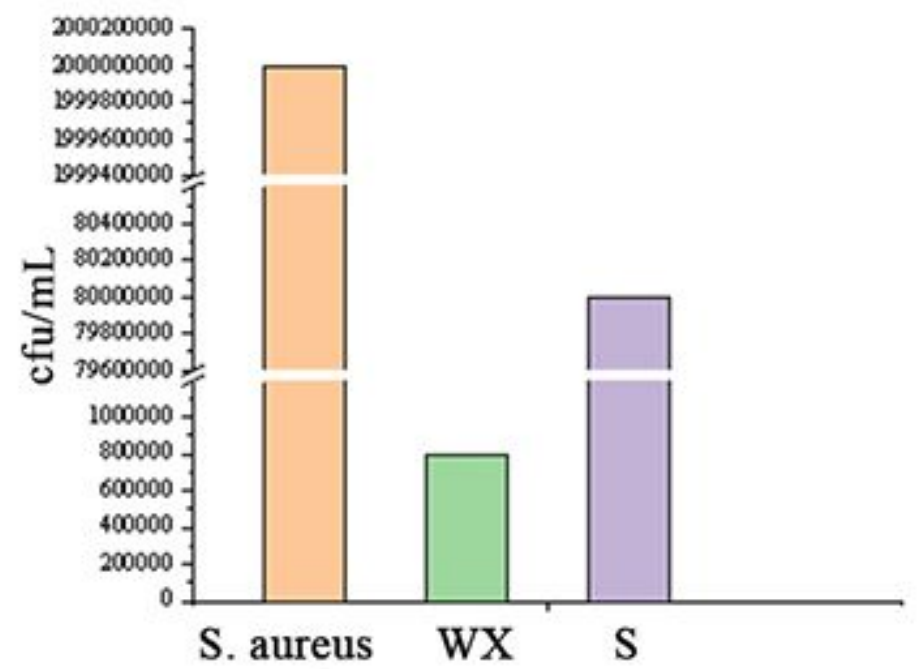

$12 \mathrm{~h}$

B

\section{Figure 6}

Effects of phage $W X$ and Streptomycin $(10 \mathrm{ug} / \mathrm{mL})$ on colony-forming unit of S. aureus. (A) Effects of phage $\mathrm{WX}$ and Streptomycin $(10 \mathrm{ug} / \mathrm{mL})$ on S. aureus (inoculation at a rate of $4 \%$ ) that culture for $24 \mathrm{~h}$. (B) Effects of phage WX and Streptomycin $(10 \mathrm{ug} / \mathrm{mL})$ on S. aureus (inoculation at a rate of $4 \%$ o), first culture for 12 hours, then phage $\mathrm{WX}$ and Streptomycin $(10 \mathrm{ug} / \mathrm{mL})$ were added and cultured for $12 \mathrm{~h}$.

\section{Supplementary Files}

This is a list of supplementary files associated with this preprint. Click to download.

- tableS1.xIsx 